\title{
Crystal Structure of 1-(2,3,4-Trimethoxybenzyl)piperazine monohydrochloride
}

\author{
Dmitrijs StePanovs and Anatoly Mishnev ${ }^{\dagger}$ \\ Latvian Institute of Organic Synthesis, 21 Aizkraukles street, Riga, LV-1006, Latvia
}

\begin{abstract}
Trimetazidine is an anti-ischemic agent. The structure of trimetazidine hydrochloride, $\mathrm{C}_{14} \mathrm{H}_{22} \mathrm{~N}_{2} \mathrm{O}_{3} \cdot \mathrm{HCl}$, was determined by X-ray crystallography. The compound crystallizes in a monoclinic system, space group $P 2{ }_{1} / c$ and cell parameters: $a=$ 21.548(1) $\AA, b=7.6273(3) \AA, c=9.5982(5) \AA, \beta=100.651(2)^{\circ}, Z=4, V=1550.32(12) \AA^{3}$. The crystal structure was solved by direct methods and refined by full-matrix least-squares on $F^{2}$ to final values of $R 1=0.055$ and $w R 2=0.118$.
\end{abstract}

(Received September 16, 2011; Accepted November 5, 2011; Published on web January 10, 2012)

Trimetazidine (1-(2,3,4-trimethoxybenzyl)piperazine) is an antiischemic agent free of hemodynamic effects. It reduces intracellular acidosis and electrolyte abnormalities by optimizing the oxygen demand of mitochondria, and by preventing a decrease in the intracellular ATP levels. ${ }^{1}$

The crystal structure of trimetazidine dihydrochloride hemihydrate $\left(\mathrm{C}_{14} \mathrm{H}_{22} \mathrm{~N}_{2} \mathrm{O}_{3} \cdot 2 \mathrm{HCl} \cdot 1 / 2 \mathrm{H}_{2} \mathrm{O}\right)$ (I) was published by Tanaka et al. in 2005. ${ }^{2}$ The title compound is trimetazidine monohydrochloride $-\mathrm{C}_{14} \mathrm{H}_{22} \mathrm{~N}_{2} \mathrm{O}_{3} \cdot \mathrm{HCl}$ (II).

The title compound (Fig. 1) was prepared as follows: after trimetazidine dihydrochloride was dissolved in methanol, a stoichiometric $\mathrm{KOH}$ alkali solution $(\mathrm{pH}=10)$ was added. In this way, colorless single crystals suitable for X-ray structure analysis were obtained. The crystal and experimental data are summarized in Table 1.

The molecular structure of the title compound, drawn by ORTEP-III, ${ }^{4}$ is shown in Fig. 2. The positions of all hydrogen atoms were calculated geometrically in the "riding" mode on the adjacent non-hydrogen atoms.

The piperazine ring takes a chair conformation in both structures I and II. The dihedral angle between the least-squares planes of the piperazine and phenyl rings is $60.3(6)^{\circ}$ for structure I and $73.6(5)^{\circ}$ for II. The torsion angle N1C7C1C2 is $98(1)^{\circ}$ in structure I and $-77.6(4)^{\circ}$ in structure II. One of three methoxy groups with the torsion angle $\mathrm{C} 5 \mathrm{C} 4 \mathrm{O} 3 \mathrm{C} 14$ equal to $-7(1)^{\circ}$ (for I) and $-3.4(5)^{\circ}$ (for II) lies close to the phenyl plane. Two other methoxy groups with $\mathrm{C} 1 \mathrm{C} 2 \mathrm{O} 1 \mathrm{C} 12$ and $\mathrm{C} 2 \mathrm{C} 3 \mathrm{O} 2 \mathrm{C} 13$ torsion angles equal to $119(1)^{\circ}$ and $-115(1)^{\circ}$, respectively, for

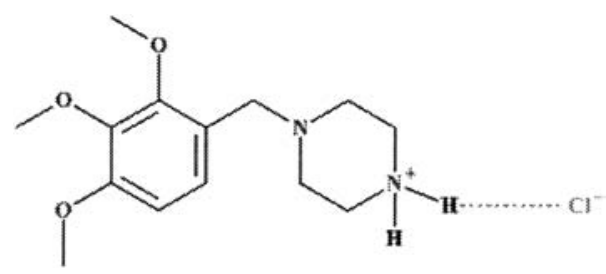

Fig. 1 Chemical diagram of the title compound.

† To whom correspondence should be addressed. E-mail: mishnevs@osi.lv structure I and $98.5(4)^{\circ}$ and $-76.8(4)^{\circ}$, respectively, for structure II, are on opposite sides of the phenyl ring. The bond lengths and angles are close to their standard values. ${ }^{6}$ There are two intermolecular $\mathrm{N}-\mathrm{H} \cdots \mathrm{Cl}$ type hydrogen bonds in the structure: $\mathrm{N} 2 \cdots \mathrm{Cl} 1=3.073(3) \AA, \mathrm{H} \cdots \mathrm{Cl} 1=2.177(1) \AA, \angle \mathrm{N} 2-\mathrm{H} \cdots \mathrm{Cl} 1=$ $172.9(2)^{\circ}$ and $\mathrm{N} 2 \cdots \mathrm{Cl} 1 *=3.121(2) \AA, \mathrm{H} \cdots \mathrm{Cl} 1 *=2.234(2) \AA, \angle$ $\mathrm{N} 2-\mathrm{H} \cdots \mathrm{Cl1} *=168.8(2)^{\circ}$. The chlorine atom marked by $*$ has the symmetry operator $-1-x ;-0,5+y ;-0,5-z$.

In the crystal by means of the hydrogen bonds, the molecules form chains along crystallographic axis $b$ (Fig. 3).

\section{Acknowledgments}

This work was supported by the European Regional

Table 1 Crystal and experimental data

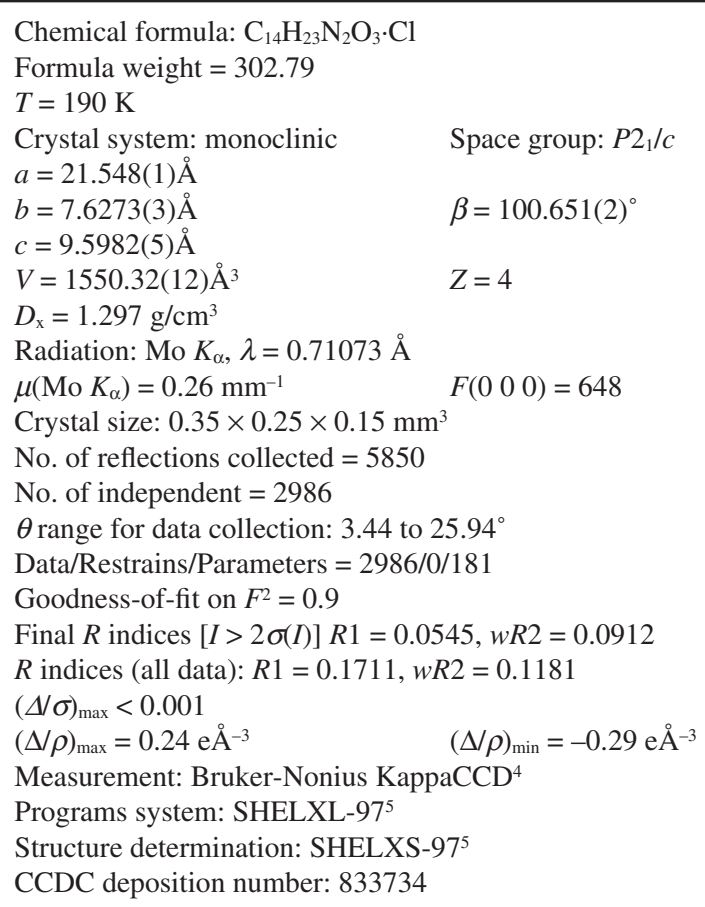




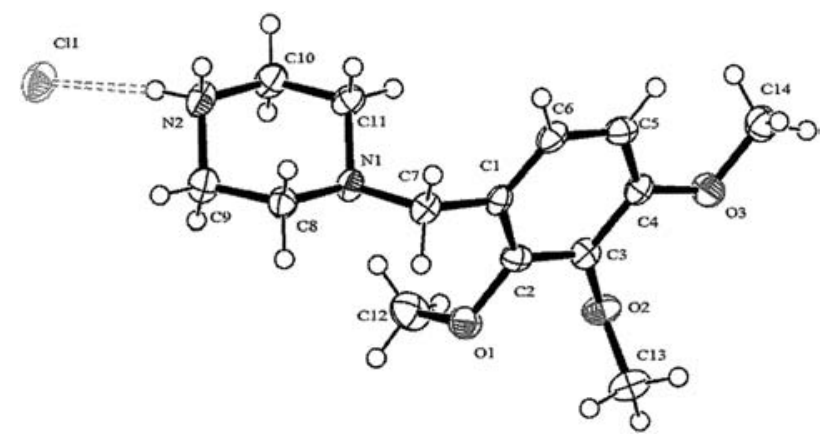

Fig. 2 The ORTEP-III $^{3}$ structure of 1-(2,3,4-trimethoxybenzyl) piperazine monohydrochloride, showing $50 \%$ probability ellipsoids; the hydrogen atoms are shown as small spheres of arbitrary radii.

Development Fund (No.2DP/2.1.1.1.0/10/APIA/VIAA/066).

\section{References}

1. A. F. Kara, Ş. Demiryürek, A. Çelik, M. Tarakçı̆̆lu, Eur. J. Pharmacol., 2004, 503, 135.

2. R. Tanaka, M. Haramura, A. Tanaka, and N. Hirayama, Anal. Sci., 2005, 21, x3.

3. L. J. Farrugia, J. Appl. Cryst., 1997, 30, 565.

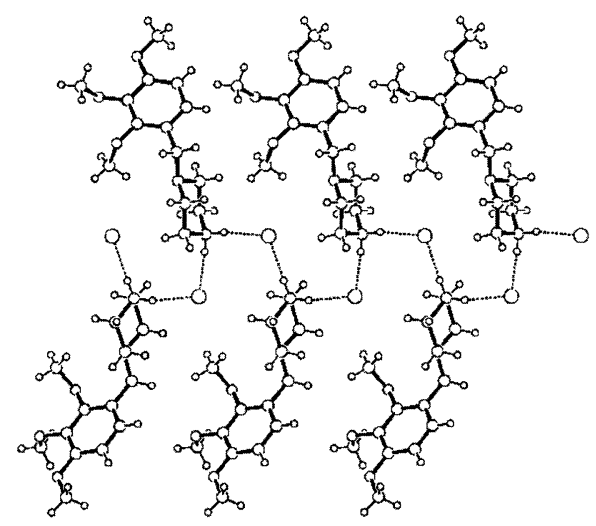

Fig. 3 Formation of $\mathrm{N}-\mathrm{H} \cdots \mathrm{Cl}$ hydrogen bond chains in the crystal structure.

4. Z. Otwinovski and W. Minor, 1997, "Methods in Enzymology, 276, Macromolecular Crystallography", Part A, ed. C. W. Carter Jr and R. M. Sweet, pp. 307 - 326, New York: Academic Press.

5. G. M. Sheldrick, Acta Cryst., 2008, A64, 112.

6. F. H. Allen, O. Kennard, D. G. Watson, L. Brammer, A. G. Orpen, and R. Taylor, J. Chem. Soc. Perkin Trans. II, 1987, S1. 